\title{
A Taxonomy of Mitigation Devices in English Language
}

\author{
Aso Ibrahim Ali ${ }^{1}$ Salah Mohammed Salih ${ }^{2}$ \\ 1 Directorate of Quality Assurance, Presidency of Koya University, Kurdistan Region, Iraq \\ ${ }^{2}$ Department of English Language, Faculty of Humanities and Social Sciences, Koya University, Kurdistan Region, Iraq
}

\begin{abstract}
Language mitigation refers to strategies that people adopt to avoid face-threatening situations in conversation and thereby to linguistically repair the damage done to someone's face by what one says or does. Previously, several studies investigating mitigation have been carried out from different perspectives, depending on the point of view adopted by each scholar. Some studies thus far have linked mitigation with politeness, whereas other studies have dealt with mitigation as an independent subject. Literature on mitigation abounds with reference to politeness strategies, euphemisms, hedges and other devices, yet there sounds to be no clear attempt to establish what substantiates mitigation. On this point, Caffi (2007, p.48) maintains that in politeness research, the notion of mitigation has so far mainly been used with reference to the set of strategies interlocutors employ to attenuate the impact of what Brown and Levinson (1987) call 'face-threatening acts' (FTAs)

The present study is designed to develop a taxonomy of mitigation types, devices, functions and strategies adopted by English language users as interpersonal goals. It also provides additional evidence with respect to the use of mitigating devices to soften illocutionary force of speech acts which are unwelcome to addresses. As for mitigation devices, there are seven major devices: Indirect Speech Acts, Tag Questions, Parenthetical Verbs, Disclaimers, Impersonal Constructions, Hedges, and Euphemism, though this last type is not referred to as a main type in previous studies. The latter two types (Hedges and Euphemism) are the backbone of mitigation devices as they subsume a variety of forms and functions. Semantic procedures are the most effective ones as they result in less direct or understated meanings.
\end{abstract}

KEY WORDS: Euphemism, Hedges, Mitigation, Politeness Strategies, Social Face

\section{INTRODUCTION}

There is always the question of how to mitigate or soften the unwelcome effect of the force of the act being performed. If an employer, for instance, wants to fire an employee, he might say directly and in plain language:

(1) You are fired!

Koya University Journal of Humanities and Social Sciences (KUJHSS),

Volume 3, Issue 1, 2020.

Received 24 July 2019; Accepted 18 September 2019,

Regular research paper: Published 17 June 2020

Corresponding author's e-mail: aso.ibrahim@koyauniversity.org Copyright (C2020 Aso I. Ali \& Salah M. Salih. This is an open access article distributed under the Creative Commons Attribution License.
Accordingly, there is an alternative way of speaking so as to reduce insofar as possible the unwelcome effects on the employee. In this case, the employer might say:

(2) It is my unpleasant task as Vice President for Personnel to bring you the bad news that we are no longer able to retain you in our employ.

In the latter case, the employer has mitigated the force of his utterance. Remarkably, mitigation is widely recognized as an analytical means when the epistemological orientation in pragmatics changes from an introspective, philosophically oriented paradigm, to an empirical one that is increasingly addressing real, non-constructed data, in contexts.

The aim of the present study is to develop taxonomy of mitigating devices in the English language. This will be accomplished by reviewing the literature on 
mitigation to find out the types, functions, structures, and strategies that constitute mitigation.

\section{MITIGATION IN LANGUAGE}

Generally, interlocutors' resort to employ mitigation in interactions to soften or reduce the illocutionary force of those speech acts which are unwelcome to addressees. Fraser (1980, p.342) points out that mitigation does not refer to "any weakening of the force of the act being performed" but is related to speech acts whose effects are "unwelcome" to the hearer. In other words, Fraser (ibid.) specifies the concept of mitigation in terms of the intention of the speaker to reduce unwelcome effects of his/her performing a certain kind of speech act. Based on Fraser's idea, Holmes (1984: 346) asserts that mitigation is a strategy used to "reduce the anticipated negative effect of a speech act". Interlocutors, for instance, may mitigate the force of a criticism, but they do not speak of mitigating their praise.

Caffi (1999, p.882), defines mitigation as "one of the two directions of modulation, namely the rhetorical stylistic encoding of an utterance, its expressivity, opposed and complementary to the direction reinforcement". Caffi (2006) finds that in everyday language, "mitigation, as an action noun, can refer both to the action of mitigating, and to the fact of being mitigated" (p.171). The former sense foregrounds the process, the latter the result. Caffi (Ibid.) further states that mitigation, as an all-embracing category employed in pragmatics, labels the wide set of strategies by which interlocutors attenuate one or more aspects of their speech. According to Vine (2010, p.339), "mitigation is oriented towards interpersonal goals". Gladwell (2008, p.194) indicates that mitigated speech refers to "any attempt to downplay or sugarcoat the meaning of what is being said".

Schneider (2010, p.255) points out that in verbal interaction, mitigation facilitates the management of interpersonal relations because it makes an utterance as acceptable as possible to the interlocutor without the speaker having to give up his or her standpoint. In other words, mitigation manages the interaction 'smoothly' and lessens the risks that the interlocutors may face on various levels. Schneider (Ibid.) calls mitigation expressions 'fine-tuning-devices' that achieve a compromise between what the speaker wants to say and what the interlocutor is willing to accept.

Caffi (2007, p.40) considers mitigation as a synonym of attenuation or downgrading and that it is the outcome of the weakening of one of the interactional parameters, which consequently involves the re-allocation and readjustment of the rights and duties triggered by the speech act, and, crucially, the weighing of their intensity and urgency. Suffice it to say, mitigation reduces obligations for the interlocutors, thus interlocutors can attain the various interactional goals easier.

Hongladarom $(2007$, p.35) exemplifies the fact that disclaimers can function as mitigation devices to help achieve interactional goals and reduce the speaker's obligation in blaming or criticizing the addressee.

Mitigation can be viewed as a weakening or downgrading that lessens the speaker's commitment to the proposition, degree of directness or indirectness of the illocution, endorsement of a social role, emotive involvement, topical salience, etc.), which constitute the system of an encounter. Further, it involves the (re-) allocation and (re-) adjustment of the rights and duties triggered by the speech act, and, crucially, the weighing of their intensity and urgency, thus interlocutors can attain the various interactional goals easier Caffi (2007).

\section{MITIGATION AS POLITENESS}

Mitigation is often viewed as part of the wider issue of politeness. Brown and Levinson (1987, p.42) treat mitigation as a synonym of politeness. Caffi (2007, p.48) maintains that in politeness research, the notion of mitigation has so far mainly been used with reference to the set of strategies interlocutors employ to attenuate the impact of what Brown and Levinson (1987) call 'facethreatening acts' (FTAs). According to Mey, 'expressions that take the edge off face-threats are often called'mitigation devices' (1993, p.73). Moreover, Caffi (1999, p.882) explicates that mitigation is employed in order to smooth interactional management by reducing risks for participants at various levels, e.g. the risk of self-contradiction (on a discourse level), the risk of refusal, conflict, or losing face (on a social level), etc., thus agreeing with the core idea of being polite.

Labov \& Fanshel (1977, pp.345-6) concede that mitigating devices do indeed mitigate conflict. As Ohbuchi, Chiba \& Fukushima (1996, p.1036) maintain, conflicts represent threats not only to the interlocutors resources or relationships but also their faces or identities. Leech (1983, p.113) postulates that the function of the tact maxim is a negative one: it is a means of avoiding conflict. Thus, it can be concluded that mitigation and politeness may serve the same function which is the attenuation of interpersonal conflicts.

Illocutionary force also has been regarded by a number of linguists as the focus of those mitigating operations that have a direct bearing on politeness. According to Leech, indirect illocutions tend to be more polite because they increase the degree of optionality, and because the more indirect the illocution is, the more diminished and tentative its force tends to be (1983, p. 64). As Arroyo (2010) concludes "the use of all kinds of mitigation and strategies of indirectness, which are conventionally associated with socially appropriate behavior, could be interpreted as compensatory 
politeness strategies in order to prevent disruption of the social order in contexts where aggressiveness and impoliteness represent the norm" (p.423).

In contrast, Fraser (1980: p.344) reveals that though it is certainly the case that a high degree of politeness and mitigation are found together, both can be regarded as distinct. In order to explicate this point, Fraser (Ibid.) exemplifies it by stating that consider the situation in which someone is the moderator at a small seminar and you are one of the participants. If she/he says, I would appreciate it if you would sit down, she/he mitigated the force of her/his request and done it politely as well. If she/he says, Please sit down, she/he has requested in a relatively polite but relatively unmitigated way. To put it in Fraser's words: the conclusion to draw from this is that "mitigation entails politeness, while the converse is not true. In short, mitigation occurs only if the speaker is also being polite" (Ibid.).

\section{PREVIOUS STUDIES}

In linguistic pragmatics, mitigation has been employed as a technical notion by linguists since the late 1970s, when making the concept of illocutionary act (Austin, 1962) operational in the analysis of discourse was a main concern in pragmatic research.

From that time onwards, some mitigation-related concepts, if not the term, are overtly or covertly referred to by researchers who worked on linguistic politeness (Leech, 1983; Brown \& Levinson, 1987; Fraser, 1990). The 'maxims of politeness' proposed by Leech (1983) in his model of discourse, in particular the 'Tact Maxim,' all have a close link with mitigation as they are based on a general 'interpersonal rhetoric,' which mainly aims at avoiding disagreement and at fostering agreement between interlocutors.

The most influential model of politeness, put forward by Brown \& Levinson (1987), regards mitigation as a synonym of politeness. Moreover, the 'face-saving view' of interaction by Fraser (1990), based on Goffman's notion of 'face' has the idea of mitigation at its core: the strategies of both positive politeness (related to social approval) and of negative politeness (related to privacy and autonomy) can be read as mitigating strategies.

Labov and Fanshel (1977) propose the notion of mitigation as opposed to that of 'aggravation'. As Labov and Fanshel (1977) comment, mitigation is employed by interlocutors to mitigate or modify their speech to avoid being offensive. Edmondson (1981) introduces three types of supportive moves, viz. grounders, expanders, and disarmers, which function as mitigators.

Along the same line, Hermann \& Weingarten (1982) and Langner (1994), who concentrate on psychotherapeutic conversation and data from college classroom interaction respectively, used the notion of mitigation as a reduction of obligations for the interlocutors. Prince et al. (1982) distinguishes two main kinds of modifications: 'approximators' (roughly corresponding to Lakoff's [1973] 'hedges') and 'shields', which convey some markedness with respect to speaker's commitment, used by doctors in order to be cautious and to weigh the degree of certainty of their utterances.

It is worth mentioning that Holmes (1984) does not only apply the concept of mitigation but indicates the ways it functions. Holmes (1984) focuses on strategies that attenuate or reinforce ('boost') illocutionary force. Moving on from, Holmes (1984) follows Fraser (1980) to treat mitigation as a particular case of attenuation to soften the predictable negative effects of a speech act. In their study on the framework of a research project on cross-cultural speech act realization(CCSARP), BlumKulka etal.'s (1989) draw a distinction between internal and external mitigation: the former occurs within the speech act, while the latter occurs outside it and corresponds to what in other frameworks are called 'presequences' or 'grounders.'

The present study is designed to develop a taxonomy of mitigation that illustrate what types, devices, functions and strategies are adopted by language users as interpersonal goals when they mitigate their speech. The present study also provides additional evidence with respect to the use of mitigating devices to soften illocutionary force of speech acts which are unwelcome to addresses.

\section{TYPES OF MITIGATION}

In his discussion of 'conversational mitigation' , Fraser (1980, p. 344) illustrates that the motivation to mitigate appears to fall into two, though not always unrelated, categories, self-serving and altruistic.

\subsection{Self-serving Mitigation}

On self-serving mitigation, Qianbo (2016, p.74) maintains that this type is "driven by fear to cause discomfort to self". According to Fraser "self-serving mitigation can be best illustrated by considering the effects on the hearer of an act, such as ordering him a distasteful task" (1980, p. 344). For instance, a director might be required by his position in an organization to order you to redraft a report, but he might be less than enthusiastic about having to do it. Consequently, he might choose a way of asking you to mitigate the effect of his order and to be relieved of some, if not all, of the responsibility of the effect of this - that you would now be required to work over your weekend and therefore be resentful towards him. He might, in fact, say something like:

(3) It is my duty as Project Director to perform the most unwelcome task of telling you that... 
Fraser (Ibid.) further explains that through employing self-serving mitigation, the speaker wishes to be 'excused' for performing the act at all, thereby defusing some of the unwelcome hearer response.

There is a second type of self-serving mitigation in which the speaker wishes to 'get off the hook', not for performing the act with its unwelcome effects, but for what doing the act implies about the speaker's beliefs. This might occur, for example, if the speaker, a physician, were to say:

(4) Difficult as it is to believe, given your life-style, the analysis shows you have a social disease.

The speaker is not asking to be excused for providing a diagnosis, but, rather, indicating that the associated implication which would arise from the fact of the disease is one which he does not wish to be committed to. (Fraser 1980, p. 344)

\subsection{Altruistic Mitigation}

Fraser (1980, p. 345) points out that in altruistic mitigation, the primary intent is only to soften the effect which the utterance has directly on the hearer rather than the effect which ultimately affects the speaker. Qianbo (2016, p.74) adds that it can be driven by fear to cause discomfort to others. For instance, in cautiously reporting that your brother has a car accident, your friend can be attempting to mitigate the effect of alarm, fear or pain, you will feel as a result of the bad news. Moreover, Fraser (Ibid.) notes that in many cases the speaker may intend to bring about both types of mitigation at once.

\section{SCOPE OF MITIGATION}

Caffi $(2007$, p.49) holds that mitigation operates on three scopes, or domains which are the proposition, the illocution, and the deictic origin of the utterance, and based on Lakoff's work (1973), she (1999, p.883) adopts the terms bushes, hedges and shields to refer to the three aforementioned domains respectively. She further maintains that "mitigating devices of all types may be employed simultaneously and, conversely, a specific mitigating device (e.g. the use of a past tense or an impersonal construction) may affect more than just one scope of the speech act" (Ibid.). Here, the main interest is to discover the way in which mitigation works.

\subsection{Bushes}

Bushes focus on the propositional content. According to Caffi (1999, p.890), bushes, which center on the interactional parameter 'precision', reduce the precision of the propositional content. As Qianbo (2016, p.76) comments, bushes decrease the weight of imposition (Brown \& Levinson, 1978) of the directive and reduce the obligation on the hearer. Suffice it to say, bushes reduce 'precision' and minimize the seriousness of the problem.

The mitigating force is usually achieved by making personal assumptions or expressing doubts about the propositional content of one's own remark on speech acts, such as offer of apology, accepting compliment, self-contradiction and confession. The representing mitigators in speech context are I think, I guess, I assume, if I could, etc.

\subsection{Hedges}

Hedges operate on the illocution of an utterance and affect the relational and emotive dimensions (Caffi1999, p.890). Moreover, Qianbo (2016, p.76) believes that as mitigators, 'hedges' are illocutionary force indicators with which speakers intend to mitigate for the sake of other-orientation on speech acts such as making an order, a request, giving advice, refusal, showing complaint, disagreement and warning such as you know, if you like, if you want, etc.

\subsection{Shields}

Caffi $(2007$, p.49) further points out that shields affect the deictic origin of the proposition. As Caffi (1999, p.895) stipulates,' in fact, in shields, the act is not mitigated by explicit linguistic means, but rather it is dislocated, displaced; there is back-grounding, defocalization, or even deletion of the utterance sourc" . Instances are the use of so to speak, let's say, by the way, for example, what's more, incidentally, etc.

The three classes of mitigators are heterogeneous. On the one hand, bushes and hedges are lexical expressions, sometimes de-semanticized, poly functional markers. As is well-known, markers are often syntactically not integrated into the sentence: hence the difficulty of ascribing them a single scope.

On the other hand, shields do not contain explicit mitigating devices: the downgrading operation takes place at a deeper, more abstract level, affecting syntax as with the passive transformation - or morphology - as in the switch from first person singular pronouns to other person pronouns. In shields there is a shift of responsibility from the ' $\mathrm{I}$ ' of the speaker, i.e. from the agent of the utterance to someone else or to an impersonal source. For instance:

(5) The histology report says that there's nothing wrong.

could be uttered instead ofI think that there's nothing wrong. In the instance (29), the ' $\mathrm{I}$ ' is deleted. Therefore, shields index an overall cognitive and emotive noncommittal to the speech act. (Caffi 2007, p.50)

\section{MITIGATING DEVICES}

Fraser (1990, pp.345-349) proposes certain mitigating devices used by interlocutors to protect themselves against various interactional risks as follows: 


\subsection{Indirect Speech Acts}

Performing indirect speech acts is certainly the most obvious way through which speakers can mitigate their intentions. Holmes (1984, p. 351) expresses that being indirect helps interlocutors to mitigate the force of their speech acts. As Fraser (1980, p.345) comments, an indirect way of requesting would be

(6) I would appreciate it if I were left alone" ,

to indicate that what one states to be their obligation to do. An important aspect of the indirect performance of speech acts for mitigation is that the specification of the intended act "...becomes less explicit, the active participation of the hearer in using both the contextual cues (including past conversations, knowledge of the world, identity of the speaker, etc.) as well as relevant conversational principles of interpretation increased" (ibid. , p.346).

Fraser (1980, p.346) notes that not every instance of indirectly performing a speech act counts as mitigation. For example, someone congratulates you indirectly by saying:

(7) I couldn't have done better myself.

The given example is indirect, but it is not considered as mitigation, since congratulations do not involve unwelcome effects.

\subsection{Impersonal Constructions}

In discussing the concept of immediacy, Fraser (1980, p.349) specifies a set of distancing techniques which consist of making non-specific reference to the speaker or the hearer. Therefore, in order to mitigate the following request, an airline flight attendant may ask his/her passengers:

(8) FAA regulations require that all passengers fasten their seat belts.

The appeal to FAA regulations creates more distance between the attendant and the passengers. And the use of all passengers rather than you creates an additional sense of non-immediacy. The distance between the request and its maker indicates that the speaker is engaging in self-serving mitigation to assure that the passengers are not going to feel antagonistic towards the attendant who appears to function as a mere instrument of others in this context.

\subsection{Disclaimers}

According to Holmes (1984, p. 359), disclaimers refer to' the possibility that the speaker is mistaken or inaccurate" . Disclaimers typically occur in sentenceinitial position. Fraser (1980, p.349) explicates that disclaimers help speakers to preface their main thought with the possibility that they may be incorrect in what follows that is nearly always a declarative with the force of a claim, judgment, diagnosis, criticism, or a similar act, at least in that context, which conveys an unwelcome effect. Examples are:

(9) Unless I 'm mistaken about the situation,

the plane is total loss. (Estimate)

you may not ever go there again. (Forbidding)

it is time to come in. (Request)

you clearly are at fault. (Criticism)

There are also other types of sentence-initial disclaimers which are restricted to directives. Instances are:

(10) If you don't mind,

sit down.

you can take it out now.

please leave at once.

do it for me.

could you spare a dime?

\subsection{Parenthetical Verbs}

Urmson (1952, p.484) shows that some parenthetical verbs help to modify or to weaken the claim to truth which would be implied by a simple assertion. Based on Urmson's work, Fraser (1980, p.348) gives the following examples to illustrate those parenthetical verbs such as conclude, suppose, guess, expect, predict that serve as mitigators:

(11) This is the road, I guess.

(12) I feel that I ought to try harder.

(13) We can, I think, do it over again.

Moreover, Urmson (1952, p.484) asserts that there are certain adverbs that can be coupled with parenthetical verbs as follows: --happily--I rejoice; unfortunately--I regret; consequently--I infer (deduce); presumably--I presume; admittedly--I admit; certainly--I know; probably-I believe. He further notes, "apart from questions of nuance of meaning the adverbs are more impersonaladmittedly suggests that what is said would be regarded by anyone as an admission whereas I admit shows only the way that the statement is to be regarded here "(Ibid.).

\subsection{Tag-Questions}

Fraser (1980, p.349) stipulates that when uttered with a rising question intonation, tag questions can be used as mitigating devices softening the force of a preceding assertive. For instance, sentences such as:

(14) You were there, weren't you?

(15) I am right, aren' $t$ I?

when uttered with a rising question intonation are characteristically regarded as a softer way of asserting 'You were there" or 'I am right' respectively.

\subsection{Hedges}

As Fraser (1980) states, "some the expression which Lakoff (1972) called 'hedges' can be used to mitigate "(p.349). If, for instance, a tax assessor gives you her/his 
finding concerning the classification of your house, she/he might tell you her/his decision via saying:

(16) Technically, your home is a multiple family dwelling.

In the example above, the hedge technically mitigates the intention of the tax assessor to avoid being thought of as personally responsible for the assessment.

\subsubsection{Forms of Hedges}

Salager-Meyer (1995, pp.131-33) offers a classification of the most widely used hedging categories:

a. Modal auxiliary verbs, the most tentative ones being: may, might, can, could, would, should:

(17) Such a measure might be more sensitive to changes in health after specialist treatment.

b. Modal lexical verbs (or the so-called "speech act verbs" used to perform acts such as doubting and evaluating rather than merely describing) of varying degree of illocutionary force: to seem, to appear (epistemic verbs), to believe, to assume, to suggest, to estimate, to tend, to think, to argue, to indicate, to propose, to speculate.

(18) In spite of its limitations, our study appears to have a number of important strengths.

c. Adjectival, nominal modal phrases, and adverbial:

i. Probability adjectives: e.g., possible, probable, un/likely:

(19) Septicemia is likely to result, which might threaten his life.

ii. Nouns: e.g., assumption, claim, possibility, estimate, suggestion:

(20) There is a possibility that the setting of the neural mechanisms responsible for this sensation is altered in patients with chronic fatigue syndrome.

iii. Adverbs (which could be considered as non-verbal modals): e.g., perhaps, possibly, probably, practically, likely, presumably, virtually, apparently.

(21) This is probably due to the fact that Greenland Eskimos consume diets with a high content of fish.

d. Approximators, adaptors as well as rounders of quantity, degree, frequency and time: approximately, roughly, about, often, occasionally, generally, usually, somewhat, somehow, a lot of.

(22) Fever is present in about a third of cases and sometimes there is neutropenia.

e. Introductory phrases such as I believe, to our knowledge, it is our view that, we feel that, which express the author's personal doubt and direct involvement.

(23) We believe that the chronic fatigue syndrome reflects a complex interaction of several factors. There is no simple explanation.

f. 'If' clauses, e.g., if true, if anything

(24) If true, then, our study contradicts the myth that fishing attracts the bravest and strongest men. g. Compound hedges comprise "strings of hedges" (i.e., the juxtaposition of several hedges). Such compound hedges can be double hedges "It may suggest that . . . ;" "it could be suggested that . . . I'), treble hedges (It would seemlikely that ...., it seems reasonable to assume), quadruple hedges (It would seem somewhat unlikely that ...), and so on.

Hedges are the most typical components of fuzzy language. Hedges can make communication smooth, moderate, polite and flexible, which effectively helps to maintain the social face of interlocutors and adjust the social relationship between speakers and hearers. Hedges serve certain functions in daily interactions which can be explicated below.

\subsubsection{Functions of Hedges}

Different classifications of hedges have been conducted due to different perspectives of study. The most influential one is put forward by Prince, Frader \& Bosk (1982) from the perspective of pragmatics. Prince, Frader \& Bosk (1982), building on the work of Lakoff (1973), attempted to address the function of hedges in an empirical study of spoken medical discourse. Prince, Frader \& Bosk (1982, p. 86) counted the number of words or phrases in their corpus which made things "fuzzier", and analyzed each item as falling into one of two main categories: approximators, which introduce fuzziness "within the propositional content proper", and shields, which introduce fuzziness "in the relationship between the propositional content and the speaker".

\section{a) Approximators}

Approximators are those hedges that can change original meaning of a proposition or provide alternative meaning to the proposition according to different situations. Simply speaking approximators can affect the original truth condition of the proposition; sometimes they even change the meaning of the proposition. As Tang (2013) comments, in verbal communication, approximators can help interlocutors avoid being assertive, speak appropriately in order to successfully achieve the purpose of communication (p.156). Approximators can be divided into adaptors and rounders.

\section{1) Adaptors}

Adaptors usually work as modifiers of terms in interactions. To put it more specifically, adaptors help to express degree of truth of the original proposition. Instances are as follows: sort of, kind of, somewhat, really, almost, quite, entirely, a little bit, to some extent, more or less, etc.

(25) Your attitude is a little rude.

In the above sentence, the speaker uses an adaptor "a little" to criticize the attitude of the other one, which 
effectively tone downs the degree of criticism and makes it more acceptable to be criticized.

\section{2) Rounders}

Tang (2013, p.156) states that rounders refer to those hedges that limit the range of subjects. Rounders are often used when it comes to measuring, especially if the exact data is missing or precise information is unavailable. Examples are approximately, essential1y, about, something between... and..., roughly, etc.

(26) The body temperature is approximately 36.9 centigrade, which is essentially the degree of a healthy condition.

The speaker used the rounder "approximately" to make sure his words are not too far away from the fact since the speaker cannot give an exact number.

\section{b) Shields}

Tang (2013, p.156) points out that unlike approximators, shields do not change the true value or the original intent of discourse structures. Shields reflect the degree of speakers' commitments to the truth value of the whole proposition they are conveying. Their functions are to moderate the tone of speakers. Shields can also be further classified into plausibility shields and attribution shields.

\section{1) Plausibility Shields}

Plausibility shields are used to show speakers' own attitude towards a proposition. According to Tang (2013), plausibility shields refer to the speakers' direct speculation of a certain subject or attitudes; they express speakers' doubtful attitude or uncertainty of the truth value of propositions (p.156).

In this case, plausibility shields usually include the first person pronouns (singular and plural), which indicates that the speakers are willing show that their statement is not absolutely right or true since it is just their own opinions. Tang (2013, p.156) illustrates that roles of the plausibility shields are to moderate the tone of speakers and avoid imposing their own thoughts on others. Plausibility shields include I think, I guess, I believe, I am afraid, I assume, I suppose, as far as I'm concerned, seem, etc.

(27) As far as I'm concerned, his proposal is the best of all that we have received.

In the above mentioned example, the expression "as far as I'm concerned" does not affect the truth condition of the original propositions; however, they are reflections of the speakers' personal stances. Meanwhile the speakers' uncertainty can be seen from the example. Tang (2013, p.156) states that in some cases, the tone can also be moderated with some modal verbs indicating speakers' doubt and inference.

(28) The change may be gradual.

\section{2) Attribution Shields}

Attribution shields are also used to express the attitude of guess or doubt, but they attribute the degree of uncertainty toward a proposition to another party. Tang (2013, p.156) believes that attribution shields do not convey the views or speculation of the speakers, but show the speakers' attitude indirectly by quoting others' perspectives. Attribution shields include according to, as is well known, the possibility will be, someone suggests that..., etc.

(29) It shows that there was presumably no acute decrease in heart rate.

Attribution shield in the above example helps to avoid the personal factors and mitigate the responsibility when speakers try to make statements.

\subsection{Euphemism}

Avoiding being offensive or impolite is a way practiced in all societies. Therefore, for better maintaining social relationship and exchanging ideas, interlocutors tend to use euphemized words. A euphemism is used as an alternative to a dispreferred expression, in order to avoid possible loss of face: either one's own face, or though giving offense, that of the audience, or of some third party (Allan \& Burridge 1991, p.11).

Euphemism is at work in many kinds of social interaction. As Wardhough (2006, p.240) says, euphemism is endemic in our society. In daily interaction, for instance, interlocutors tend to use the expression the euphemized expression go to the bathroom instead of urinate to avoid being impolite.

Euphemism can be formed through a variety of procedures. Semantic procedures are the most effective ones as they result in less direct understated meanings. Euphemisms can be categorized into five types (Williams 1975; Shipley 1977; Rawson 1983; Neaman \& Silver 1983; Allan \& Burridge 1991). This is based on the basis of semantic procedure, or how euphemistic words are linguistically created.

\section{1) Shortening}

When encountering words that people dare not to mention, they replace them with shortened words, so that there are number of different processes, such as:

\section{a. Abbreviation}

According to Meyer (2009, p.181), abbreviations are similar to acronyms in that they are composed from a set of initials of words, but unlike acronyms, they are pronounced as a series of letters like S.O.B. for 'son-of-abitch' or $B A B$ is an abbreviation used to euphemize the expression Buang Air Besar (which is also a euphemism that indirectly means to defecate).

\section{b. Apocopation}

This process can be defined as the way to shorten or omit the last syllable of a word, such as Vamp for Vampire.

\section{c. Back Formation}


According to Neaman \& Silver (1990: 346), the backformation of words refer to the substitution of one part of speech with a shortened form for another; for example, burgle is derived from burglar and is a euphemism for rob.

\section{d. Diminutive}

This procedure is the formation of new terms by shortening a name and adding a suffix to indicate affection or smallness such as the word buttocks is euphemized as heinie which is the diminutive of hindend.

\section{e. Omission}

This involves leaving out the letters of taboo words after the initial, such as S--- instead of Shit. (Allan \& Burridge, 1991, p.12)

\section{f. Clipping}

Shipley $(1977$, p. 28) believes that clipping is the deletion of same part of a longer to give a shorter word with the same meaning; as in, bra for brassiere and jeeze for Jesus Christ.

\section{2) Circumlocution}

Allan \& Burridge (1991, p. 2) state that using longer expressions is called circumlocution. Euphemisms which have more letters and syllables are deployed in place of a single one, such as A Middle Eastern dancing which sounds better than belly dance, and Solid human waste is a euphemism of faeces.

\section{3) Remodeling}

"The sound of words can be altered to conceal something that is offensive." (Allan \& Burridge, 1991, p.2). This can involve a variety of processes of largely verbal play, such as follows:

\section{a. Phonological Distortion}

Euphemisms can be created when the speakers intentionally distort the pronunciation of words, such as crumbs, crust or cripes for Christ. The same applies to the word hell which is euphemized as heck.

\section{b. Blending}

Yule (2006, p.55) points out that blending is the combination of the first part of one word with the second part of another word to produce a single new term. Allan \& Burridge (1991, p. 3) however, propose that most blending words involve portmanteau words such as strewth which means God's wrath, zounds as God's wounds, and drat as God's rot.

\section{c. Reduplication}

As Burridge (2006, p.456) says, reduplication is a process whereby syllables or letters of two are repeated; for instance, jeepers creepers for 'Jesus Christ', twiddlediddles 'testicles', and rantum-scantum 'copulate'.

\section{4) Semantic Change}

New types of euphemisms can be obtained from a number of semantic processes:

\section{a. Semantic Shift}

The semantic shift, with reference to Rawson (1981, p.15), is the substitution of the whole, or a similar generality for the specific part which is not discussed; for example, rear and becomes bottom or with somebody are transformed into ' to go to bed with somebody'. In addition to this, Allan \& Burridge (1991, p.6), propose the same strategy in euphemizing expressions into two categories, such as General-for-specific and Part-for-whole euphemisms. The general-for-specific strategy is a oneto-one substitution, such as the use of go to bed instead of having sex. The part-for-whole strategy is the reference to specific ideas such as when one needs to 'go to the lavatory', or when one says' we spend a penny these ones derived from the payment for a public toilet of a penny.

\section{b. Metaphorical Transfer}

Actually, a good many of current vulgarisms and obscenities, for which interlocutors now need euphemisms, may themselves have originally been euphemistic metaphors (Williams, 1975, p.201). Glow for sweat and blossom for pimple are clear examples.

\section{c. Widening}

According to Williams (1975, p.200), widening minimizes the impact of semantic features of a word by moving up one level of generality to name a superordinate set, usually omitting the specific features that would unequivocally identify the referent e.g. growth (cancer), foundation (girdle), solid human waste (feces).

\section{d. Litotes}

This type of euphemism is created by replacing a word with the negative expression of its opposite. Thus, one may say untidy or unclear instead of dirty, not bad instead of fair, untruthful instead of lying and unwise for foolish.

\section{e. Understatement}

Understatement reduces the risk in showing an apparent meaning; for example, a nuclear reactor that is said to be above critical is actually out of control, sleep for die, and not bright for fool (Allan \& Burridge, 1991, p.5).

\section{f. Indirection}

Rawson (1981, p.9) asserts that too touchy topics and terms maybe alluded to in various ways by mentioning one aspect of the subject, circumstance involving it, or a related subject; Thus, people really do come together in an assembly center and soldiers do stop fighting when they break off contact with the enemy, but these are indirect euphemisms for "prison" and "retreat," respectively.

\section{g. Abstraction}

As Rawson (1981, p.9) comments, some words (it, problem, situation, and thing) help cast ideas in the widest possible terms and make ideal cover-up words. For instance, an economic thing might refer to the state of slump, recession, or depression.

\section{5) Borrowing}

In addition to these types, using words borrowed from foreign languages to function as euphemisms can also lead to many other types, such as follows: 


\section{a. External Borrowing}

According to Burridge (2006, p.457), "using words borrowed from other languages to function as euphemisms is characteristic of many languages". Borrowing refers to the taking over of words from other languages. French and Latin, for instance, provide English with many of its euphemisms for bodily effluvia, sex, and the associated acts and bodily organs; for example, perspire instead of sweat, expectorate instead of spit, defecate and faeces instead of shit.

\section{b. Internal Borrowing}

Euphemisms can also be borrowed from different sublanguages. Technical jargon provides euphemisms such as treponemal disease, luetic disease, spirachoetal disease for 'syphilis'. The antithetical strategy is the use of slang items like cupid's measles for 'syphilis'. (Burridge 2006, p.457)

The above discussion about types, scopes and devices of language mitigation will be presented in a fresh taxonomy in figure (1) below:
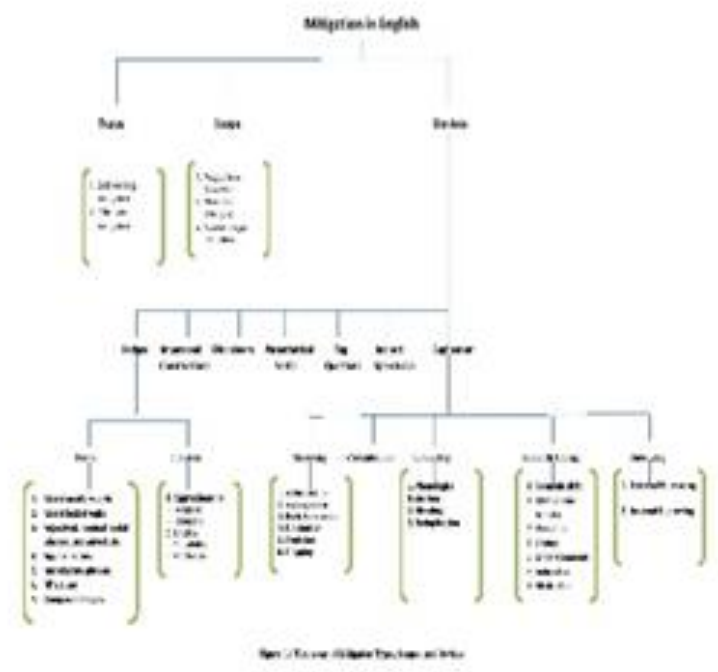

The above taxonomy categorizes mitigation into three main fields: types, scope, and devices. The first field, types, subcategorizes them into two main subtypes: selfserving and altruistic. The second category, scope, covers three main subcategories: proposition, illocution, and deictic origin. The most fruitful yet intricate category is the third category, devices, which subsumes seven subcategories (hedges, impersonal constructions, disclaimers, parenthetical verbs, tag questions, indirect speech acts, and euphemism), each of which has its own devices.

The most important of these devices are hedges and euphemism. Hedges subsume forms and functions. There are seven hedging forms: modal auxiliary verbs, modal lexical verbs, adjectival, nominal modal and adverbial, approximants, introductory phrases, if clauses and compound hedges. Functions are of two main types: approximators (adaptors and rounders) and shields (plausibility and attribution). Euphemism incorporates five subcategories: shortening (abbreviation, apocopation, back formation, diminutive, omission, and clipping), circumlocution, remodeling (phonological distortion, blending, and reduplication), semantic change (semantic shift, morphological transfer, widening, litotes, understatement, indirection, and abstraction) and borrowing (external and internal).

\section{CONCLUSIONS}

In conclusion, mitigation accentuates the interlocutors' identities both as social actors and as interacting persons as it soothes out the interactional processes by presenting interlocutors as considerate, tactful, thoughtful, and empathetic, and thus makes the attainment of interactional goals easier. The following are the most salient points that have been drawn from the discussion and of the above taxonomy:

- While in the literature on mitigation, there has been an attempt to equate mitigation with politeness, it can be argued that mitigation is the internal modifications in speech whose purpose is to downplay or soften the effect of the speech act whereas politeness is a choice of an overall strategy.

- Types of mitigation should not be confused with devices as the former constitutes functions per se, while the latter represents the syntactic, semantic, morphological and discoursal devices adopted by interlocutors to mitigate their speech.

- Euphemism has been found to constitute a main type of mitigation, though this was not referred to as such in previous studies.

- The two types, hedges and euphemism, are the backbone of mitigation devices as they subsume the most effective ways to mitigate speech.

- Among the category of euphemism, semantic change can be the most effective one as it subsumes devices such as widening, litotes, understatement, indirection, and abstraction that can result in less direct or understated meanings.

\section{REFERENCES}

Allan, K and Burridge, K (1991), Euphemisms and Dysphemism: Language Used as Shield and Weapon, Oxford University Press, New York.

Arroyo, JLB (2010), 'Interpersonal issues in political discourse', in M A Locher \& S L Graham Schneider (eds), Interpersonal pragmatics, De Gruyter Mouton, Berlin, pp. 405-434.

Brown, P and Levinson, SC (1987), Politeness: some universals in language usage, Cambridge University Press, Cambridge. 
Burridge, K (2006), 'Taboo, euphemism, and political correctness', Encyclopedia of Languages \& Linguistics, pp. 455 - 462.

Caffi, C (1999), ‘On mitigation', Journal of Pragmatics,vol. 31, no. 7, pp. 881-909.

Caffi, C (2006), 'Mitigation', in K. Brown (ed), Encyclopedia of language and linguistics, Elsevier, Oxford, pp. 171-175.

Caffi, C (2007), Mitigation, Elsevier, Amsterdam.

Fraser, B (1980), 'Conversational mitigation', Journal of Pragmatics, vol.4, no.4, pp. 341-350.

Gladwell, M (2008), Outliers: the story of success, Little, Brown and Company, New York.

Holmes, J (1984), 'Modifying illocutionary force', Journal of Pragmatics, vol.8, no.3, pp. 345-365.

Hongladarom, K (2007), 'Don't blame me for criticizing you ... : a study of metapragmatic comments in Thai', in W Bublitz\& A Hubler (eds), Metapragmatics in use, John Benjamins Publishing Company, Amsterdam, pp. 29-47.

Labov, W \& Fanshel, D (1977), Therapeutic discourse: psychotherapy as conversation, Academic Press, New York.

Lakoff, R. (1973). The logic of politeness: Or, minding your p's and q's. In C. Corum, T. Cedric Smith-Stark, \& A. Weiser (Eds.), Papers from the 9th Regional Meeting of the Chicago Linguistic Society. Chicago Linguistic Society, 292-305

Leech, GN (1983), Principles of pragmatics, Longman, New York.

Mey, JL (1993), Pragmatics: an introduction, Blackwell, Oxford.

Meyer, CF (2009), Introducing English linguistics, Cambridge University Press, Cambridge.

Neaman, J and Silver, C (1990), Kind Words: A Thesaurus of Euphemisms, McGraw Hill publishers, Inc, New York.

Ohbuchi, K, Chiba, S \& Fukushima, O (1996), 'Mitigation of interpersonal conflicts: politeness and time pressure', Personality and Social Psychology, vol.22, no.10, pp. 1035-1042.

Prince, E, Frader, J \& Bosk, C (1982), 'On hedging in physician physician discourse', in R. J. Di Pietro (ed.), Linguistics and the Professions. Proceedings of the Second Annual Delaware Symposium on Language Studies, NJ: Ablex, Norwood, pp. 8397.

Qianbo, L (2016), 'Mitigating mechanism of discourse markers', Canadian Social Science, vol.12, no.12, pp. 74-78

Rawson, H (1981), A Dictionary of Euphemisms and Other Double Talk, Crown Publishers, New York.

Salager-Meyer, F (1995), 'I think that perhaps you should: a study of hedges in written scientific discourse', The Journal of TesolFrance, vol. 2, no.2, pp.127-143.

Schneider, S 2010), 'Mitigation', in M ALocher\& S L Graham Schneider (eds), Interpersonal pragmatics, De Gruyter Mouton, Berlin, pp. 253-269.

Shipley, J (1977), In Praise of English: the Growth and Use of Language, New York Times publishers, New York.

Tang, J (2013), 'Pragmatic functions of hedges and politeness principles', International Journal of Applied Linguistics \& English Literature, vol. 2, no. 4, pp. 155-160.

Urmson, JO (1952), 'Parenthetical verbs', Mind, vol. 61, no. 244, pp. 480496.
Vine, B (2010), 'Interpersonal issues in the workplace', in M A Locher\& S L Graham Schneider (eds), Interpersonal pragmatics, De Gruyter Mouton, Berlin, pp. 329-351.

Wardhaugh, R (2006), An introduction to Sociolinguistics, 5th ed, Blackwell Publishing Ltd, Oxford. 